\title{
The drought risk of maize in the farming-pastoral ecotone in Northern China based on physical vulnerability assessment
}

\author{
Zhiqiang Wang ${ }^{1,2}$, Jingyi Jiang ${ }^{2,3}$, and Qing Ma $^{4,5}$ \\ ${ }^{1}$ National Disaster Reduction Center/Satellite Application Center for Disaster Reduction of the Ministry of Civil Affairs, \\ Beijing 100124, China \\ ${ }^{2}$ Key Laboratory of Disaster Reduction and Emergency Response, Ministry of Civil Affairs, Beijing 100124, China \\ ${ }^{3}$ INRA-EMMAH UMR 1114, 84914 Avignon, France \\ ${ }^{4}$ College of Geography, Beijing Normal University, Beijing 100875, China \\ ${ }^{5}$ Chongqing No.18 High School, Chongqing 400020, China \\ Correspondence to: Jingyi Jiang (jiangjingyi1989@163.com)
}

Received: 6 June 2016 - Published in Nat. Hazards Earth Syst. Sci. Discuss.: 30 June 2016

Revised: 10 November 2016 - Accepted: 19 November 2016 - Published: 15 December 2016

\begin{abstract}
Climate change is affecting every aspect of human activities, especially the agriculture. In China, extreme drought events caused by climate change have posed a great threat to food safety. In this work we aimed to study the drought risk of maize in the farming-pastoral ecotone in Northern China based on physical vulnerability assessment. The physical vulnerability curve was constructed from the relationship between drought hazard intensity index and yield loss rate. The risk assessment of agricultural drought was conducted from the drought hazard intensity index and physical vulnerability curve. The probability distribution of drought hazard intensity index decreased from south-west to north-east and increased from south-east to north-west along the rainfall isoline. The physical vulnerability curve had a reduction effect in three parts of the farming-pastoral ecotone in Northern China, which helped to reduce drought hazard vulnerability on spring maize. The risk of yield loss ratio calculated based on physical vulnerability curve was lower compared with the drought hazard intensity index, which suggested that the capacity of spring maize to resist and adapt to drought is increasing. In conclusion, the farmingpastoral ecotone in Northern China is greatly sensitive to climate change and has a high probability of severe drought hazard. Risk assessment of physical vulnerability can help better understand the physical vulnerability to agricultural drought and can also promote measurements to adapt to climate change.
\end{abstract}

\section{Introduction}

Climate change and its influence on human activity have gained more and more attention from different fields and communities. In the past 30 years, the global surface temperature kept the linear growth trend and the frequency and intensity of extreme climate events increased (IPCC, 2014). Even though many measures have been taken to tackle climate change, these tendencies will remain. In arid areas, water shortage resulting from climate change during the crop growing stage will lead to loss of yield, increasing frequency of agricultural drought and threatened food security (FAO, 2013; Wheeler and von Braun, 2013). In Africa, climate change will amplify existing stress on water availability and agricultural systems, particularly in semi-arid environments. In Asia, agricultural productivity for crops like rice will decline because of climate change in many subregions (IPCC, 2014). For China, drought is one of the most obvious performances of climate change (Piao et al., 2010). In the past 60 years, China has suffered a number of severe drought hazards, which caused great loss of agricultural production (Zou et al., 2005). A hazard is a dangerous phenomenon, substance, human activity or condition that may cause loss of life, injury or other health impacts, property damage, loss of livelihoods and services, social and economic disruption, or environmental damage (UNISDR, 2009). Better understanding and evaluation of agricultural drought hazard can help people improve the ability to respond to agricultural drought 
hazard and put forward countermeasures to reduce risk of agricultural drought hazard in high-risk areas.

Risk is defined as the combination of the probability of an event and its negative consequences (UNISDR, 2009). As the core of disaster risk assessment, studies of vulnerability have been widely applied in many different fields, such as ecology, public health and global climate change (Füssel, 2007). Initially, vulnerability was defined as the human response to hazard events (Blaikie and Cannon, 2004; FAO, 2001). Gradually, vulnerability has acquired new meanings, including how the different systems of human society respond to hazard, the interaction process of factors like nature, society, economy and environment (UNDP, 2004), the sensitivity or susceptibility to hazards and the capacity to cope with hazards and adapt to them (IPCC, 2014). Many methods have been proposed to assess vulnerability. Statistical method builds the relationship between impact factors and vulnerability to reflect the characteristic of vulnerability (Simelton et al., 2009), but this method cannot consider different kinds of factors synthetically. Other kinds of methods, like fuzzy modelling or the multi-indicator method (AntwiAgyei et al., 2012; Kim et al., 2015), can provide a compressive assessment for different impact factors. However, the fuzzy modelling method is restricted by background knowledge and information. Therefore, it is hard to set weight for different indicators. For the multi-indicator method, some information will be dropped during the process of integrating different indicators. Cluster analysis method can consider different impact factors separately and determine the most vulnerable places based on different combinations of the components of vulnerability (Sharma and Patwardhan, 2008). The advantage of this method is its ability to maintain information from different factors completely. Compared with fuzzy modelling and the multi-indicator method, the cluster analysis method can provide richer information for decision makers. However, this method is always restricted to a qualitative description of vulnerability, and it cannot quantitatively describe the vulnerability of a hazardaffected body.

However, none of the studies discussed above consider physical factors and social factors separately. This restricts the ability of the model to separate the mechanism of disaster from it formation. Different from the system vulnerability caused by social factors, physical vulnerability is an internal characteristic of hazard-affected bodies. It is the capacity of a hazard-affected body to respond to, resist and recover from a strike caused by nature or human beings (Wang et al., 2013). Many studies have quantitatively analysed the physical vulnerability of different disasters: Uzielli et al. (2008) utilised the relationship between landslide intensity and the susceptibility of vulnerable elements to quantitatively estimate physical vulnerability of the built environment and population to landslides. Douglas (2007) used fragility curves to model physical vulnerability for evaluation of earthquake and landslide risk. For physical vulnerability of agricultural drought hazard, most studies chose geographical statistical methods or a different drought index with meteorology, hydrology or remote sensing data to calculate the distribution of drought hazard risk (Kellner and Niyogi, 2014; Karavitis et al., 2014; Jain et al., 2015; Murthy et al., 2015). However, none of these studies considered the relationship between meteorological factors and crop water stress during the process of crop growth, making it hard to determine the physical vulnerability of crops to drought hazard. Based on the crop growth model, Wang et al. (2013) proposed a hazard-loss curve to construct the relationship between drought hazard intensity and crop yield loss, and they utilised the curve to simulate the physical vulnerability of hazard-affected crops with an environmental-policy-integrated climate (EPIC) model. Since the drought hazard intensity is calculated from the accumulation of crop daily water stress, the physical vulnerability curve can better reflect the biophysics regulation during crop growth and avoid errors caused by the integration of multi-parameters. Physical vulnerability curve makes the drought hazard vulnerability become a parameter, which can be described quantitatively in a dynamic process and provides the probability for assessing physical vulnerability of agricultural drought hazard from the aspect of disaster mechanism.

To construct the physical vulnerability curve, the key point is to calculate the drought hazard intensity index and the corresponded crop yield loss ratio. In a previous study (Wang et al., 2015), a new method was proposed to determine drought hazard intensity index based on the daily water stress from the EPIC model and yield loss contribution rates for different growth stages. In this study, the risk assessment of agricultural drought was conducted from the physical vulnerability curve. Firstly, under the circumstances of no irrigation, the drought hazard intensity index was calculated from the daily water stress and yield loss contribution rates for different growth stages. Based on the distribution of drought hazard intensity index, the risk of drought hazard intensity index in different regions was analysed. Then, the yield loss ratio was obtained from the difference of yield with two different scenarios (sufficient irrigation and no irrigation). With the spatial distribution of drought hazard intensity index, sites with a different drought hazard intensity index and yield loss ratio were selected. A logistic model was used to simulate the physical vulnerability curve of crops from the relationship between hazard and loss. According to the physical vulnerability curve, both the physical vulnerability assessment and risk assessment of yield loss ratio were analysed.

Ecotone is defined as a multi-dimensional environmental interaction zone between ecological systems (Hufkens et al., 2009). Because of its sensitivity to climatic variation, environmental change and human activity, an ecotone tends to shift in space and time over several spatial scales (Kark, 2013). For example, the African Sahel is regarded as a typical ecotone that is influenced by fluctuations in climate and human activities (Herrmann et al., 2005; Rian et al., 2009). 
In East Asia, the farming-pastoral ecotone in Northern China stretching across the monsoon fringe area from the southwest to the north-east is dominated by adjacent ecological systems of steppes and crops (Lu and Jia, 2013). As a typical ecotone with the largest area and longest span in the world, the farming-pastoral ecotone in Northern China is highly sensitive to climate change in East Asia. Many researchers utilised historical meteorological data, including temperature, precipitation and remote sensing data, to compositely analyse the impacts of climate change and socioeconomic factors on boundary shifts and land-use change of the farming-pastoral ecotone in Northern China (Liu et al., 2011; Ye and Fang, 2013; Geng et al., 2014; Shi et al., 2014). Results show that the extent of the farming-pastoral ecotone in Northern China greatly fluctuated in accordance with the variability of precipitation ( $\mathrm{Lu}$ and Jia, 2013; Geng et al., 2014). Meanwhile, the dry climate conditions and long-term excessive human activity have made desertification in this region a serious environmental problem that affects the economy and societal development (Xu et al., 2014). Based on the simulation from a land-use scenario dynamic model, it is predicted that the farming-pastoral ecotone in Northern China will become increasingly vulnerable with hotspots for landuse change because of intensified drying trends (Geng et al., 2014). Therefore, the farming-pastoral ecotone in Northern China was chosen as the study area in this study. In addition, since spring maize, which is a kind of drought-resistant crops, is widely planted in this region, it was selected as a typical crop for the risk assessment of physical vulnerability in the farming-pastoral ecotone in Northern China. The assessment results showed that the farming-pastoral ecotone in Northern China is a region with a high risk of agricultural drought. To better adapt to drought, more attention should be paid in this region and more methods such as changing the growth environment of crops to reduce the strength of drought hazard intensity index, developing improved varieties of crops to reduce physical vulnerability of agricultural drought and reducing crop exposure to drought during the planting process should be adopted in response to climate change.

\section{Data and methodology}

\subsection{Study area and data}

\subsubsection{Study area}

The farming-pastoral ecotone in Northern China is sensitive to climate change and belongs to a rain-fed agricultural region that is fragile in ecology based on agricultural drought hazard risk assessment of this region. It can reflect the spatial-temporal variation of drought hazard resulting from climate change. There exist many different definitions of the farming-pastoral ecotone in Northern China.
In general, it is located in the northern part of China, with the rainfall isoline changing from 300 to $400 \mathrm{~mm}$, annual precipitation change ranging from 15 to $30 \%$ and dryness change ranging from 1.0 to 2.0 (Zhao et al., 2002). The precipitation period is between June and August with large interannual variation. According to the distribution of landform and vegetation zonality, the farming-pastoral ecotone in Northern China can be classified into three parts: the eastern part, the middle part and the western part. The eastern part is the transition area of the Northeast China Plain and the Inner Mongolian Plateau, with vegetation types changing from warm temperate deciduous forests to temperate forest steppe. The annual average temperature ranges from 3 to $7^{\circ}$. The middle part transitions from the North China Plain to Loess Plateau with the vegetation changing from warm temperate deciduous forests to temperate grassland. Because of the relatively high altitude, the annual average temperature here ranges from 0 to $1^{\circ}$. The western part is the transition area from the Loess Plateau to the Qinghai-Tibet Plateau, with the vegetation changing from warm temperate deciduous forests to temperate desert steppe. The annual average temperature ranges from 6 to $9^{\circ}$. Figure 1 shows the location and the land use of the farming-pastoral ecotone in Northern China. The eastern part, middle part and western part of the farming-pastoral ecotone in Northern China are located from east to west respectively. The blue triangles represent 54 meteorological stations covering the whole region and the yellow regions are cultivated land. Different shades of black lines show the change of rainfall isolines, which increase from north-west to south-east and extend along the direction of north-east to south-west.

\subsubsection{Data}

The data used in this study include meteorological data of the farming-pastoral ecotone in Northern China from 1966 to 2011, soil data and agricultural data (Table 1). The daily meteorological data came from 54 meteorological stations in the study area. Daily solar radiation information was recorded at 27 stations. The daily solar radiation data for the remaining stations were estimated based on the sunshine duration data using the Angstrom-Prescott model (Angstrom, 1924; Prescott, 1940). The soil texture data were retrieved from "Chinese Soil Genus Records" and transformed into the USDA soil-type system (Skaggs et al., 2001).

\subsection{Methodology}

The process of assessment is shown in Fig. 2. Since the disaster risk $(R)$ is the function of hazard factor $(H)$, physical vulnerability $(V)$, exposure $(E)$ and the disaster reduction capacity of the hazard-affected body to hazard $\left(C_{\mathrm{H}}\right)$, physical vulnerability $\left(C_{\mathrm{V}}\right)$ and exposure $\left(C_{\mathrm{E}}\right)$ (Eq. 1$)$, under the assumption that all maize was exposed to drought hazard, both hazard intensity index and the physical vulnerability curve 


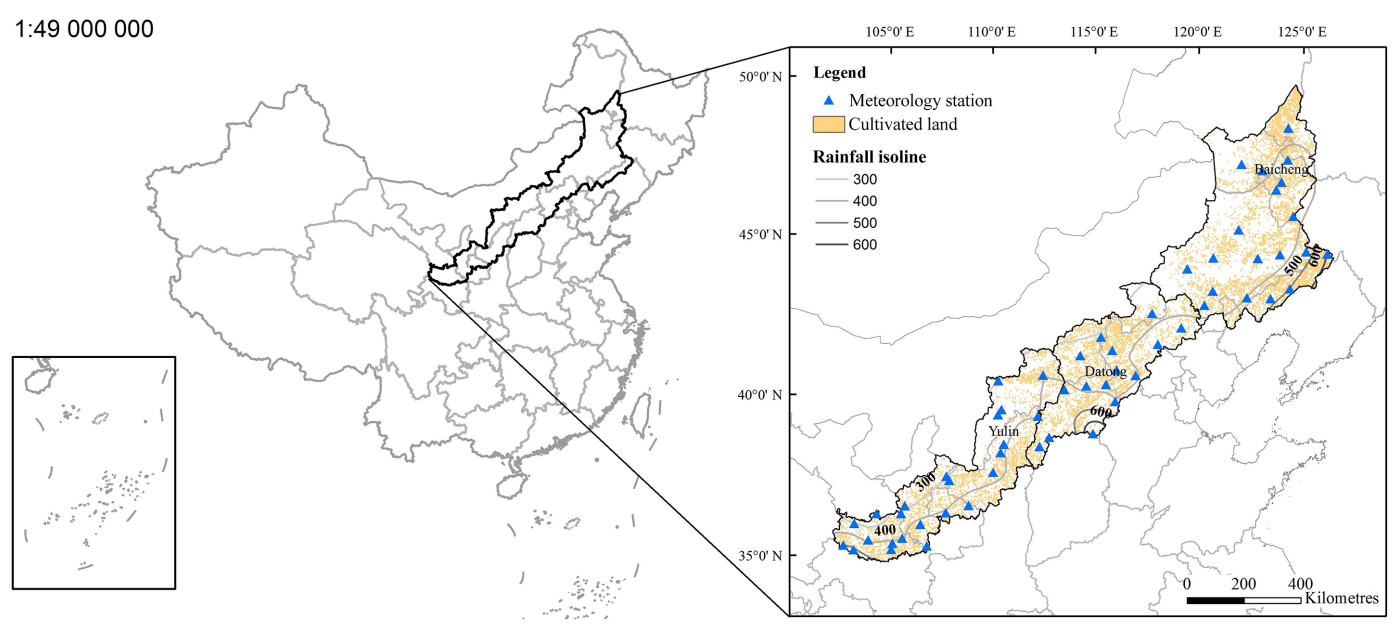

Figure 1. Location and the land-use map of the farming-pastoral ecotone in Northern China.

Table 1. Meteorological, soil and relative agricultural data

\begin{tabular}{lll}
\hline Database & Content & Source \\
\hline Meteorological data & $\begin{array}{l}\text { Daily data from 1960 to 2011: precipitation, } \\
\text { temperature, radiation, wind speed and } \\
\text { relative humidity }\end{array}$ & $\begin{array}{l}\text { China meteorological data sharing service } \\
\text { system of the China Meteorological Adminis- } \\
\text { tration }\end{array}$ \\
\hline Spatial distribution of soil & $1: 1000000$ soil map of the study area & $\begin{array}{l}\text { Institute of Soil Science, Chinese Academy } \\
\text { of Sciences }\end{array}$ \\
\hline Soil properties & $\begin{array}{l}\text { Soil layers, texture data, organic carbon } \\
\text { and so on }\end{array}$ & Chinese Soil Genus Records \\
\hline Land-use map & $\begin{array}{l}\text { Land-use map of the study area in 2000. The } \\
\text { main land-use type includes paddy field, dry } \\
\text { land, forest land, grassland and so on }\end{array}$ & $\begin{array}{l}\text { Institute of Remote Sensing and Digital } \\
\text { Earth Chinese Academy of Sciences }\end{array}$ \\
\hline Statistical agricultural data & $\begin{array}{l}\text { Fertilisation, sowing area, yields from } \\
\text { 1966 to 2011 }\end{array}$ & China Statistical Yearbook \\
\hline
\end{tabular}

were simulated with the EPIC model to assess the risk of spring maize in the farming-pastoral ecotone in Northern China.

$R=\frac{H \times V \times E}{C_{\mathrm{H}} \times C_{\mathrm{V}} \times C_{\mathrm{E}}}$

The station EPIC model was used to calibrate the genetic parameter of local maize. Then a water-deficit experiment on different growth stages was conducted to calculate the yield loss contribution rate. Therefore, the maize drought hazard intensity index was defined based on daily water stress and the yield loss contribution rate. Added with the spatial data in the time series, the spatial EPIC model was used to calculate the spatial maize drought hazard intensity index. Meanwhile, the yield loss ratio was obtained from the difference of yield under two different simulated scenarios with the EPIC model (One was sufficient irrigation and the other one was no irrigation). After this, the physical vulnerability curve was constructed from sites under different drought hazard intensity using logistic regression model to describe the relationship between drought hazard and yield loss. According to the function of disaster risk, the risk assessment of drought hazard was conducted from three aspects: the first aspect was the risk assessment of drought hazard intensity index, the second was physical vulnerability assessment of spring maize based on a physical vulnerability curve and the third one was the risk assessment of yield loss ratio calculated from a physical vulnerability curve.

\subsubsection{Drought hazard intensity index}

The EPIC model is a field-scale crop model that is capable of simulating daily crop growth, calculating crop yield under various climate and environmental conditions and performing long-term simulations for hundreds of years (Gassman et al., 2005). In recent years, the EPIC model has been applied in different fields, including climate change (Izaurralde 


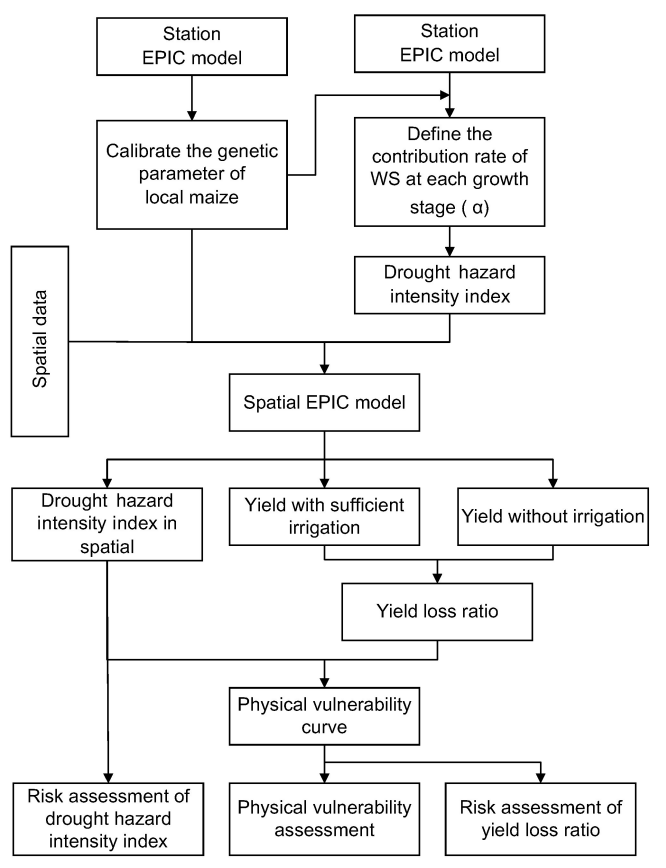

Figure 2. Flow chart of drought risk based on physical vulnerability assessment.

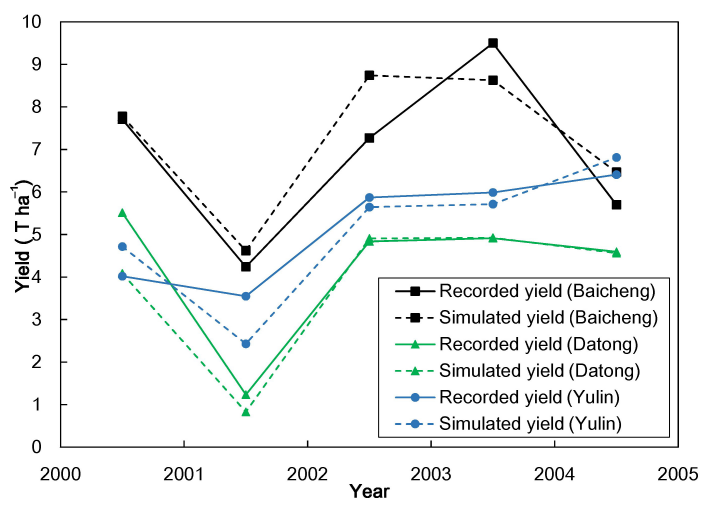

Figure 3. Calibration of the genetic parameters using the recorded yields of spring maize at Baicheng, Datong and Yulin stations.

et al., 2012; Rinaldi and De Luca, 2012), simulation of crop yields (Pumijumnong and Arunrat, 2013; Xiong et al., 2014) and drought disaster risk assessment (Jia et al., 2012; Wang et al., 2013). For different kinds of crops, genetic parameters used in the EPIC model vary with different varieties and geographical conditions. Therefore, before simulation with the EPIC model, it is necessary to localise the genetic parameters of crops based on the field measurements. In addition, parameters like soil parameters, filed management parameters and daily meteorological data are also input parameters for running EPIC model.

According to the three parts of the farming-pastoral ecotone in Northern China defined in the last section, we chose three representational stations (eastern part: Baicheng, mid-

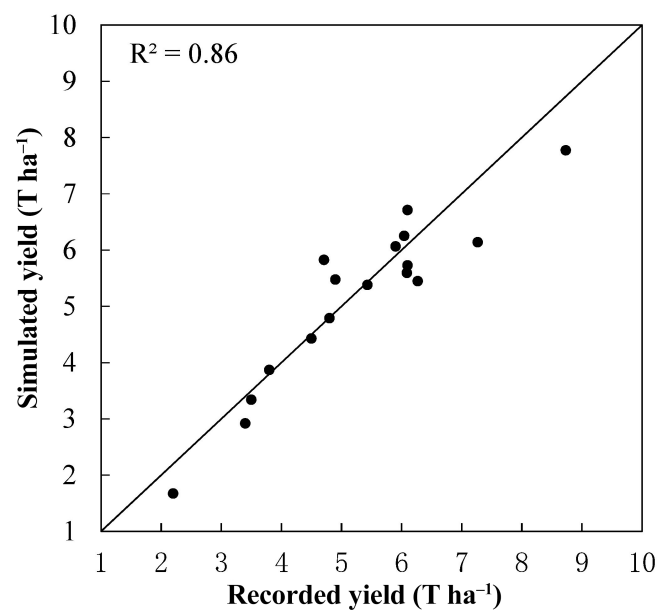

Figure 4. Validation of the genetic parameters using the recorded yields of spring maize at six stations in the study area from 2000 to 2005.

dle part: Datong, western part: Yulin) to calculate genetic parameters of spring maize for each part. At each station, the annual yields of spring maize from 2000 to 2005 from agricultural statistic yearbooks were selected as the recorded yields to adjust the genetic parameters. In addition, the daily meteorological data from 2000 to 2005, the soil data and the field management data were all put into the station EPIC models. The genetic parameters such as energy biomass conversion factor and harvest index were finally determined after a number of adjustments based on the comparison between the model output crop yields and the recorded data. The simulation results of spring maize for each station are demonstrated in Fig. 3. To validate the accuracy of the determined genetic parameters, the annual yields from agricultural statistic yearbooks at another six stations (Chifeng, Tongliao, Zhangjiakou, Jining, Guyuan and Dingxi) within the study area from 2000 to 2005 were selected. Figure 4 shows the validation results between the simulated results and the recorded yields. The correlation coefficient $R^{2}$ is 0.86 . Seen from the validation result, the determined genetic parameters of spring maize were appropriate for this study. For the difference between simulated results and recorded data, errors mainly came from the input data of the station EPIC models, including daily meteorological data and yield management data.

After running the EPIC model, parameters that describe the growth state of crops are output. Among them, water stress, which can reflect the relationship between water supply and demand during the crop growth process, is an important parameter in risk assessment of agricultural drought. Therefore, during the calculation of drought hazard intensity index, water stress is selected as the main factor to describe the intensity of drought. In addition, because water stress will have a different influence on crop yield in different crop growing stages, so the yield loss contribution rate of water 
Table 2. Yield loss contribution rate $\alpha$ at Baicheng, Datong and Yulin.

\begin{tabular}{|c|c|c|c|c|c|c|c|c|}
\hline & & \multicolumn{7}{|c|}{ Growth stage of stage maize } \\
\hline & & $\begin{array}{r}\text { Seeding } \\
\text { stage }\end{array}$ & $\begin{array}{r}\text { Jointing } \\
\text { stage }\end{array}$ & $\begin{array}{r}\text { Early } \\
\text { heading } \\
\text { stage }\end{array}$ & $\begin{array}{r}\text { Late } \\
\text { heading } \\
\text { stage }\end{array}$ & $\begin{array}{r}\text { Early } \\
\text { grain-filling } \\
\text { stage }\end{array}$ & $\begin{array}{r}\text { Late } \\
\text { grain-filling } \\
\text { stage }\end{array}$ & $\begin{array}{r}\text { Mature } \\
\text { stage }\end{array}$ \\
\hline Yield loss & Baicheng & 0.17 & 0.22 & 0.18 & 0.18 & 0.16 & 0.09 & 0 \\
\hline contribution & Datong & 0.16 & 0.25 & 0.19 & 0.16 & 0.15 & 0.08 & 0 \\
\hline Rate $\alpha_{i}$ & Yulin & 0.17 & 0.18 & 0.22 & 0.17 & 0.16 & 0.10 & 0 \\
\hline
\end{tabular}

stress $(\alpha)$ (Wang et al., 2015), which is calculated from the proportion of yield reduction rate in each stage to the summary of the yield reduction rate in different stages (Eq. 2), is also used to reflect water critical periods for crop yields. Based on crop growth regulation, $m$ stages of crop growth are defined.

$\alpha_{i}=\frac{\text { yield }_{i}}{\sum_{i=1}^{m} \text { yield }_{i}}$,

where yield $_{i}=Y_{i} / Y_{\mathrm{S}}, Y_{\mathrm{S}}$ is the yield under sufficient soil water supply and $Y_{i}$ is the yield under water shortage in growth stage $i$. The number of growth stages is $m$.

Based on the EPIC water stress and the calculated yield loss contribution rate, the equation of drought hazard intensity index is as follows (Wang et al., 2015):

$\mathrm{DHI}_{y j}=\frac{\sum_{k=1}^{n} \alpha_{i}\left(1-\mathrm{WS}_{k}\right)}{\operatorname{maxDHI}}$,

where $\mathrm{DHI}_{y j}$ is the drought hazard intensity index of $y$ year in unit $j, \mathrm{WS}_{k}$ is the water stress on day $k, \alpha_{i}$ is the yield loss contribution rate of $\mathrm{WS}_{k}$ and $k$ belongs to the $i$ growth stage, $n$ is the total days when there is water stress; max DHI denotes the maximum value of $\sum_{k=1}^{n} \alpha_{i}\left(1-\mathrm{WS}_{k}\right)$ in all the simulated years and units. $\mathrm{DHI}_{y j}$ varies from 0 (0 represents the minimum intensity of drought hazard) to 1 (1 represents the maximum intensity of drought hazard).

\subsubsection{The establishment of the physical vulnerability curve}

To determine the impact of water stress on crop yields, both the crop genetic parameters and daily meteorological data after spatial interpolation are put into the spatial EPIC model. With soil nutrients and ventilation guaranteed, two scenarios ( $Y 1$ : sufficient irrigation, $Y 2$ : no irrigation) are set to simulate the growth of the crop. For each unit, the difference of crop yields between two scenarios for each year is the year yield loss under water stress. The proportion between the year yield loss and the maximum yield with sufficient irrigation for multiple years in this unit is defined as the yield loss ratio under water stress (Wang et al., 2013a):

$\mathrm{YL}_{y j}=\frac{Y 1_{y}-Y 2_{y}}{\max Y 1_{j}}$

where $\mathrm{YL}_{y j}$ is the loss rate of yield of $y$ year in station $j$, $Y 1_{y}$ and $Y 2_{y}$ are the unit yields of $y$ year under scenarios $Y 1$ and $Y 2$ and $\max Y 1_{y}$ represents maximum unit yield of station $j$.

Based on drought hazard intensity index and the corresponding yield loss rate, the physical vulnerability curve is defined to simulate the relationship between them using the regression analysis method. For each kind of crop, the physical vulnerability curve is an internal property for the hazardaffected body itself. The key point for establishing the physical vulnerability curve is setting up a wide range of scenarios from no drought to extreme drought hazard. The more scenarios of drought hazard intensities that are included, the more accurate the physical vulnerability curve will be. In this study, according to the drought hazard intensity index we calculated from different evaluation units in different years, we try to select more sites under different scenarios of drought hazard intensities. Then the logistic regression analysis is used to simulate the physical vulnerability curve of the crop from selected points.

\subsubsection{Risk assessment of agricultural drought}

In this study, drought hazard intensity index and physical vulnerability curve are the two cores of the drought risk assessment. Based on the formulation process of agricultural drought hazard, the risk assessment of the drought hazard intensity index, the physical vulnerability assessment of spring maize and the risk assessment of yield loss ratio calculated from the physical vulnerability curve were conducted sequentially. For drought hazard intensity index, since it is calculated from crop daily water stress and yield loss contribution rate, it can reflect the degree of agricultural drought on a specific crop. Therefore, the time series, standard deviation and slope of the drought hazard intensity index on each evaluation unit were calculated to analyse the spatial-temporal distribution of agricultural drought. The probability distribution of the drought hazard intensity index was processed for the risk assessment. For the physical vulnerability assess- 

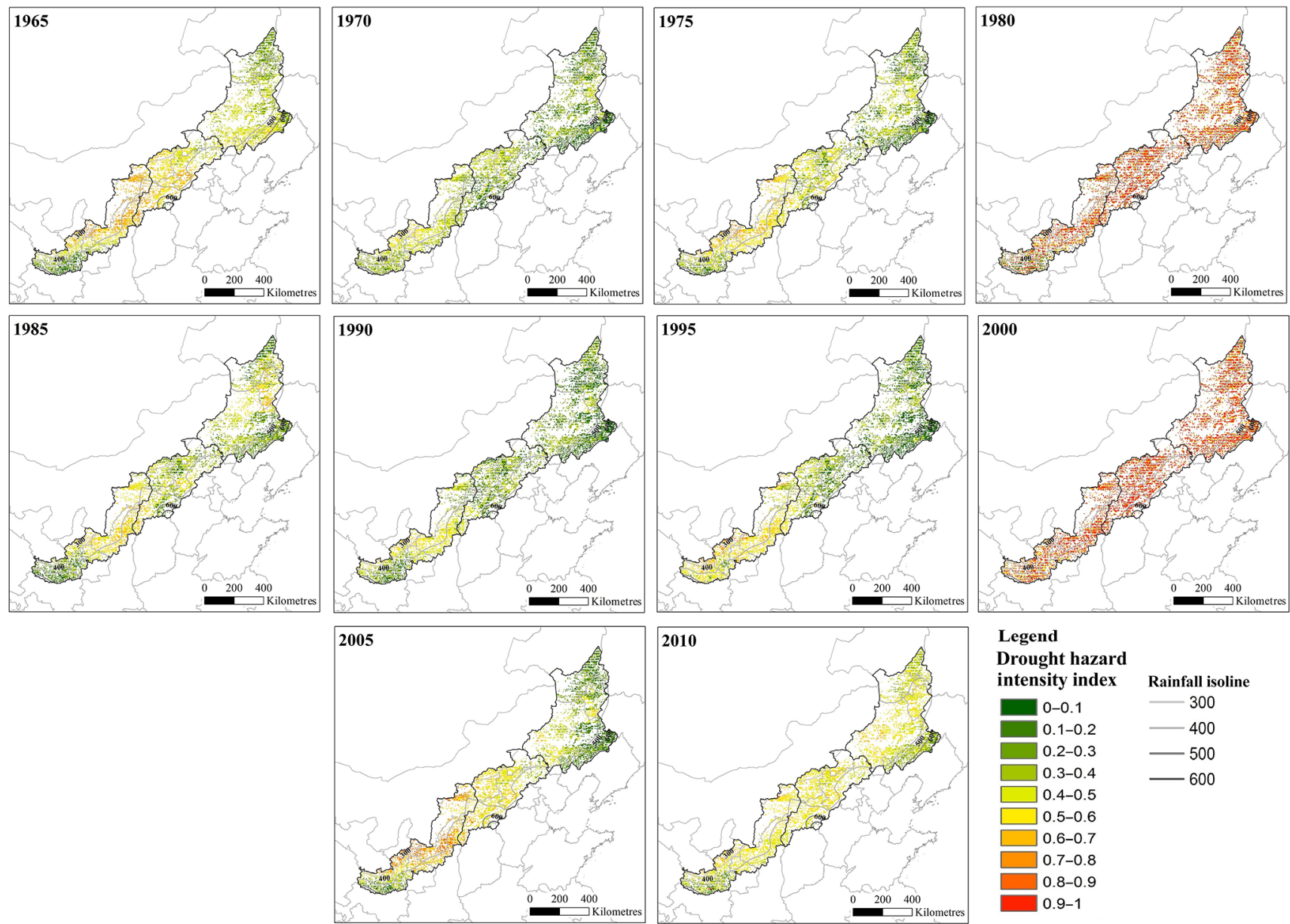

Figure 5. The spatial distribution of spring maize drought hazard intensity index in time series.

ment, it was conducted relying on the physical vulnerability curve of spring maize. For the yield loss ratio calculated from the physical vulnerability curve, since it is determined by both drought hazard intensity index and the corresponding physical vulnerability, the calculated yield loss ratio is a good representative of drought risk. The standard deviation, slope and probability of yield loss ratio were calculated to show the spatial-temporal distribution and probability distribution of drought risk.

\section{Results}

\subsection{Risk assessment of maize drought hazard intensity index}

Based on the classification method of annual crop climate types (AQSIQ/SAC, 2008), 2002 was selected as the climate normal year to calculate the yield loss contribution rates of water stress at Baicheng, Datong and Yulin with the corresponding genetic parameters of the spring maize. According to the growth regulation of spring maize, six growth stages were determined in Table 2. With the crop yield under sufficient irrigation as the comparison, the water-deficit treatment in each growth stage was conducted with each station EPIC model. The resulting yield losses were recorded. According to Eq. (2), the yield loss contribution rates in different growth stages for each station were shown in Table 2. For more details about the experiment on water deficit, Wang et al. (2015) is referenced.

We used the genetic parameters and yield loss contribution rates from three sites to represent genetic parameters and yield loss contribution rates in the eastern, middle and western parts of the farming-pastoral ecotone in Northern China. With the evaluation unit of $5 \mathrm{~km} \times 5 \mathrm{~km}$ area, the interpolated meteorological data from 1966 to 2011 and the genetic parameters for each part were put into the spatial EPIC model. Under the condition of no irrigation, the daily water stress of each evaluation unit in the study area was output. Based on Eq. (3), the spatial distribution of drought hazard intensity index of the farming-pastoral ecotone in Northern China was finally calculated. 


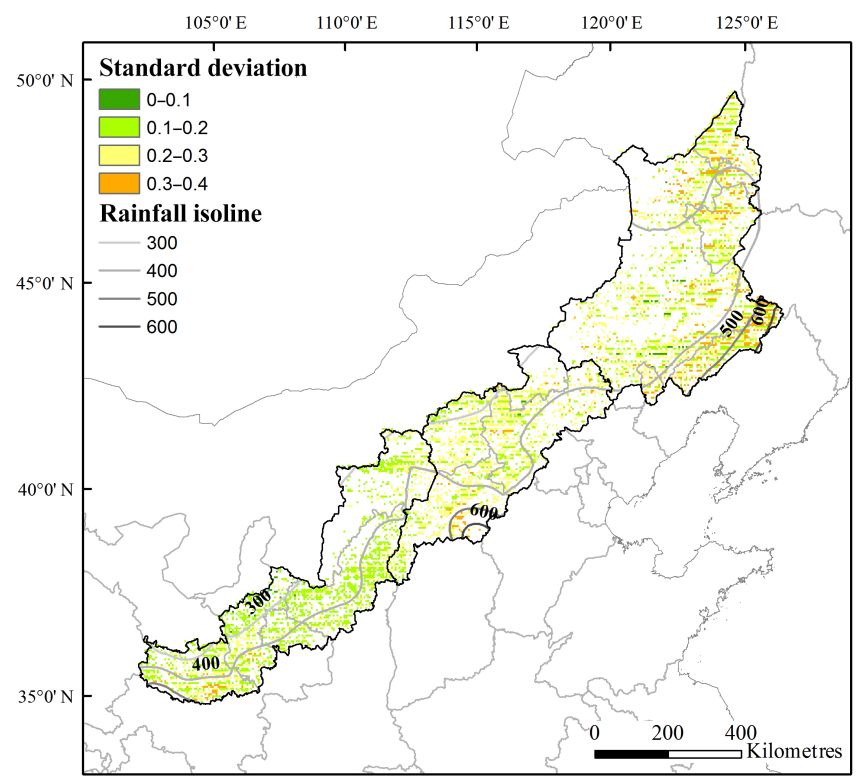

Figure 6. Standard deviation of spring maize drought hazard intensity index from 1966 to 2011.

Figure 5 shows the distribution of spring maize drought hazard intensity index in the farming-pastoral ecotone in Northern China for every fifth year. For most years, the drought hazard intensity index of spring maize increased from north-east (0.1) to south-west (0.5) and decreased back to 0.1 at the margin of south-west. Compared with the rainfall isoline, there existed a negative correlation between the drought hazard intensity index and precipitation. For regions with rainfall isoline lower than $300 \mathrm{~mm}$, drought hazard intensity index for most years was around 0.5 or 0.6 . However, with the rise of precipitation, drought hazard intensity index declined gradually. For regions with rainfall isoline from 500 to $600 \mathrm{~mm}$, most drought hazard intensity indexes centred on 0.1 . In general, the middle part and most regions of the western part were the driest part of the whole study area, with an average drought hazard intensity index for multiple years larger than 0.5 .

Seen from the time series of drought hazard intensity index in the farming-pastoral ecotone in Northern China, there existed two extreme drought hazards in 1980 and 200, with the average drought hazard intensity index larger than 0.8 . For other years, areas with a drought hazard intensity index larger than 0.5 were mainly centred in the western part. A cyclic behaviour with a return period of approximately 20 years appears from 1965 to 2000. Since 2005, regions with a drought hazard intensity index larger than 0.5 spread north-eastward. In 2010, except little areas, the drought hazard intensity index for the whole study ranged from 0.4 to 0.6 .

To reveal the fluctuation of drought hazard intensity index of spring maize in time series, the standard deviation from 1966 to 2011 of each evaluation unit in the study area was

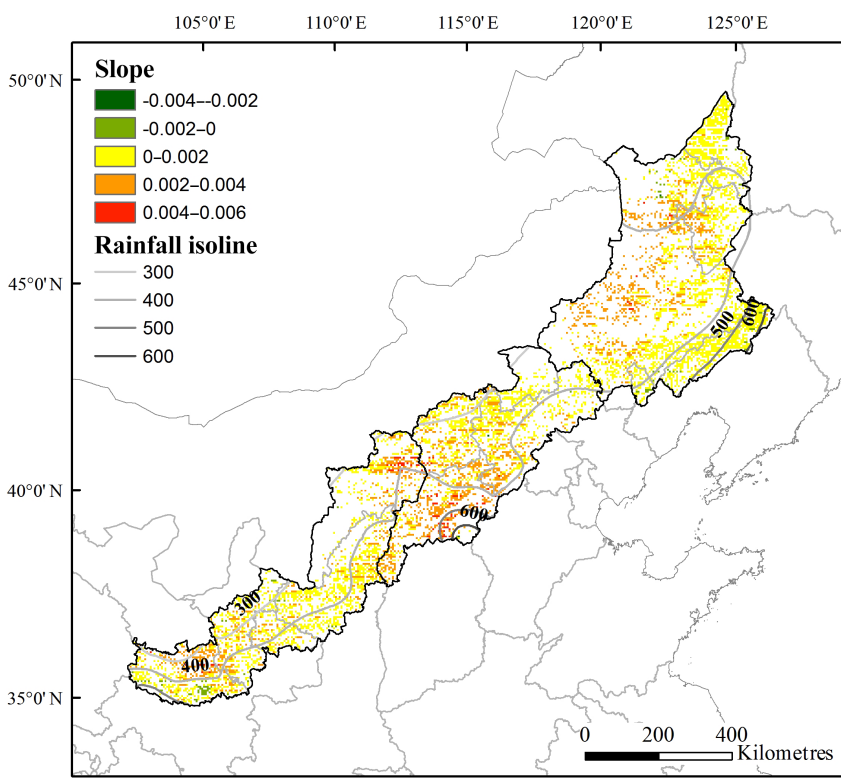

Figure 7. Slope of the linear regression of spring maize drought hazard intensity index from 1966 to 2011.

calculated. Figure 6 is the distribution of standard deviation of spring maize drought hazard intensity index from 1966 to 2011. For most parts, the standard deviation was from 0.1 to 0.3 and had the tendency of decreasing from north-east to south-west. The eastern part had the highest standard deviation (0.3), which showed the greatest interannual fluctuation of spring maize drought hazard intensity index. But the standard deviation in the western part ranging from 0.1 to 0.2 was relatively low.

In order to describe the variation tendency of drought hazard intensity index from 1966 to 2011 in the farming-pastoral ecotone in Northern China, the slope of the linear regression of drought hazard intensity index for 46 years was calculated. Figure 7 is the distribution of the slope of spring maize drought hazard intensity index from 1966 to 2011. Warmtoned colours like red and yellow represent a slope larger than 0 and the increasing tendency of drought hazard intensity index, while cool-toned colours like green represent a slope smaller than 0 and the decreasing tendency of drought hazard intensity index. For the whole farming-pastoral ecotone in Northern China, the change of slope was small, ranging from -0.006 to 0.006 . But for most parts, the slope was larger than 0 , which meant the intensity of drought hazard strengthened. The middle part had the most obvious increasing tendency (from 0.002 to 0.006 ). Next was the eastern part within the rainfall isoline from 300 to $400 \mathrm{~mm}$ and then a little region at the south-west edge of the study area with the slope changing from 0.002 to 0.004 .

To access the risk of spring maize drought hazard intensity index in the farming-pastoral ecotone in Northern China, we calculated the exceeded probability of spring maize drought 

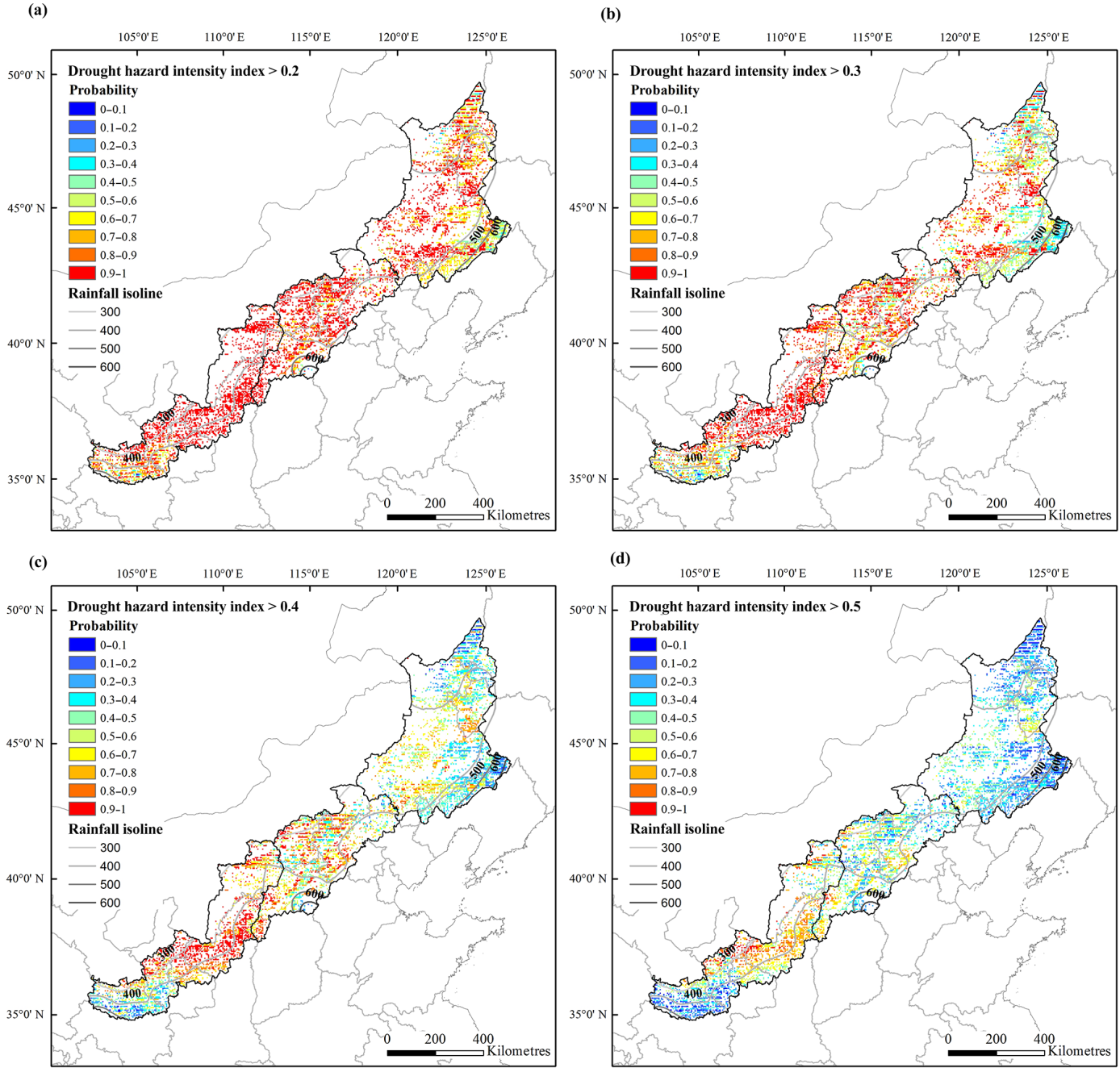

Figure 8. Probability distribution of spring maize drought hazard intensity index for different hazard levels. (a) Drought hazard intensity index $\geq 0.2$ (b) drought hazard intensity index $\geq 0.3$, (c) drought hazard intensity index $\geq 0.4$, (d) drought hazard intensity index $\geq 0.5$.

hazard intensity index for each evaluation unit. Through fixing the drought hazard intensity index, probability distribution of spring maize drought hazard intensity index with 4 hazard levels was drawn separately: spring maize drought hazard intensity index $\geq 0.2$ (Fig. 8a), spring maize drought hazard intensity index $\geq 0.3$ (Fig. 8b), spring maize drought hazard intensity index $\geq 0.4$ (Fig. 8c) and spring maize drought hazard intensity index $\geq 0.5$ (Fig. 8d).

Seen in Fig. 8, the high-value area of the probability was located mostly in the western part and middle part, while the low value area was located in the eastern part within the rainfall isoline from 500 to $600 \mathrm{~mm}$ and the south-west edge of the western part. For most regions of the western part, the upper limit of probability was 1 under four hazard levels. Therefore, the probability is very high that drought hazard and large disaster losses will occur every year. For the middle part, the upper limit of probability under 4 hazard levels from 0.2 to 0.5 was $1,1,0.8$ and 0.5 . Consequently, in this region, drought hazard with the intensity index of 0.2 and 0.3 will occur nearly every year. The risk level of drought hazard with the intensity index of 0.5 was every 2 years. For these two low-value regions, the upper limit of probability under 4 hazard levels from 0.2 to 0.5 was $1,0.9,0.4$ and 0.2 . These regions will have a drought hazard with the intensity index of 0.2 every year and the risk level of drought hazard with the intensity index of 0.5 at least every 5 years.

\subsection{Physical vulnerability curve of spring maize}

Based on the genetic parameters of spring maize for three parts of the farming-pastoral ecotone in Northern China, the spatial EPIC model was conducted under two scenarios $(Y 1$ : sufficient irrigation, $Y 2$ : no irrigation). For each evaluation unit, the loss rate of yield was obtained according to Eq. (4). Combined with the spatial distribution of the drought hazard intensity index, 50 sites under different drought hazard 

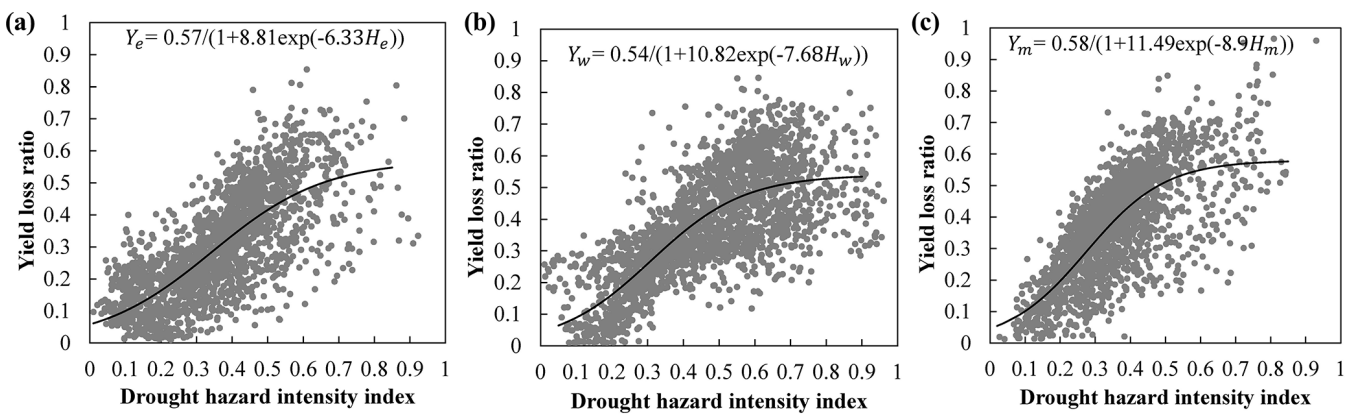

Figure 9. Physical vulnerability curve to drought hazard of spring maize in the (a) eastern part (b) middle part and (c) western part of the farming-pastoral ecotone in Northern China.

intensities were selected for each part to extract drought hazard intensity index and the corresponding loss rate of yield for 46 years. For each part of the farming-pastoral ecotone in Northern China, a scatter diagram that describes the drought hazard intensity curve and yield loss rate is shown in Fig. 9. Each point represents the annual loss rate of yield and drought hazard intensity for a given site. The solid line is the physical vulnerability curve simulated using logistic curve fitting methodology. For each part, the physical vulnerability of spring maize could be evaluated using the physical vulnerability curve as follows:

$$
\begin{aligned}
& Y_{\mathrm{e}}=\frac{0.57}{\left(1+8.81 \times 10^{-6.33 H_{\mathrm{e}}}\right)}, \\
& Y_{\mathrm{m}}=\frac{0.58}{\left(1+11.49 \times 10^{-8.9 H_{\mathrm{m}}}\right)}, \\
& Y_{\mathrm{w}}=\frac{0.54}{\left(1+10.821 \times 10^{-7.68 H_{\mathrm{w}}}\right)},
\end{aligned}
$$

where $Y_{\mathrm{e}}, Y_{\mathrm{m}}$ and $Y_{\mathrm{w}}$ represent the yield loss ratios of spring maize in the eastern, middle and western parts and $H_{\mathrm{e}}, H_{\mathrm{m}}$ and $H_{\mathrm{w}}$ are the drought hazard intensity indexes in the eastern, middle and western parts, respectively. $R^{2}$ is 0.70 for the eastern part, 0.71 for the middle part and 0.65 for the western part.

Restricted by the meteorological data, it was hard to include every different meteorological scenario in theoreticallike extreme drought $(H=1)$ or no drought $(H=0)$ to simulate a real physical vulnerability curve for drought hazard of spring maize. In addition, errors from meteorological data and the model itself might also have impacts on simulation results. Considering the accuracy of the input data and some uncertainties during the calculation process, the simulated drought physical vulnerability curve of spring maize for each part was satisfied in this study.

Comparing three different kinds of spring maize planted in the study area, the physical vulnerability curve of spring maize for each part is slightly different. However, as these three regions are adjacent and are all located in the farmingpastoral ecotone in Northern China, which is relatively dry, the difference is not obvious. For each curve, at the beginning stage the yield loss ratio is mild, with low drought hazard intensity index (0 to 0.2$)$. Then the increase of yield loss ratio is swift, with middle drought hazard intensity index $(0.2$ to $0.6)$. For the last stage, the yield loss ratio reaches the highest point and becomes stable, with high drought hazard intensity index (0.6 to 1$)$. For each part of the study area, all of these curves are below or near the $1: 1$ line, which shows the reduction effect of drought hazard intensity and the reduction of drought hazard vulnerability on spring maize.

\subsection{Risk assessment of yield loss ratio based on the physical vulnerability curve}

We assumed that the spring maize in the study area was completely exposed to drought hazard, making the drought risk of spring maize mainly determined by the drought hazard intensity index and its vulnerability under this drought hazard intensity. Therefore, in this section we put the calculated drought hazard intensity index of each evaluation unit into the physical vulnerability curve to get the simulated yield loss ratio. The risk assessment was conducted on the basis of the distribution of yield loss ratio for each unit.

To describe the change of yield loss ratio in time series, both the standard deviation and the slope of yield loss ratio from 1966 to 2011 were calculated for each evaluation unit. Figure 10 is the distribution of standard deviation of yield loss ratio in the farming-pastoral ecotone in Northern China. Similar to the standard deviation of the drought hazard intensity index, the standard deviation of yield loss ratio also showed the tendency to decline from north-east to south-west. Conversely, because of the reduction effect of the physical vulnerability curve, the standard deviation of yield loss ratio was slightly lower than that of the drought hazard intensity index. Here the standard deviation of yield loss ratio for the eastern part was from 0.1 to 0.3 . For the middle and western parts, it ranged from 0 to 0.2. Consequently, the interannual instability of yield loss was reduced. Figure 11 is the slope of linear regression of yield loss ratio. Slope larger than 0 is showed with warm-toned colours and represents the increasing tendency of yield loss ratio, while slope smaller than 0 is showed with cool-toned colours and 


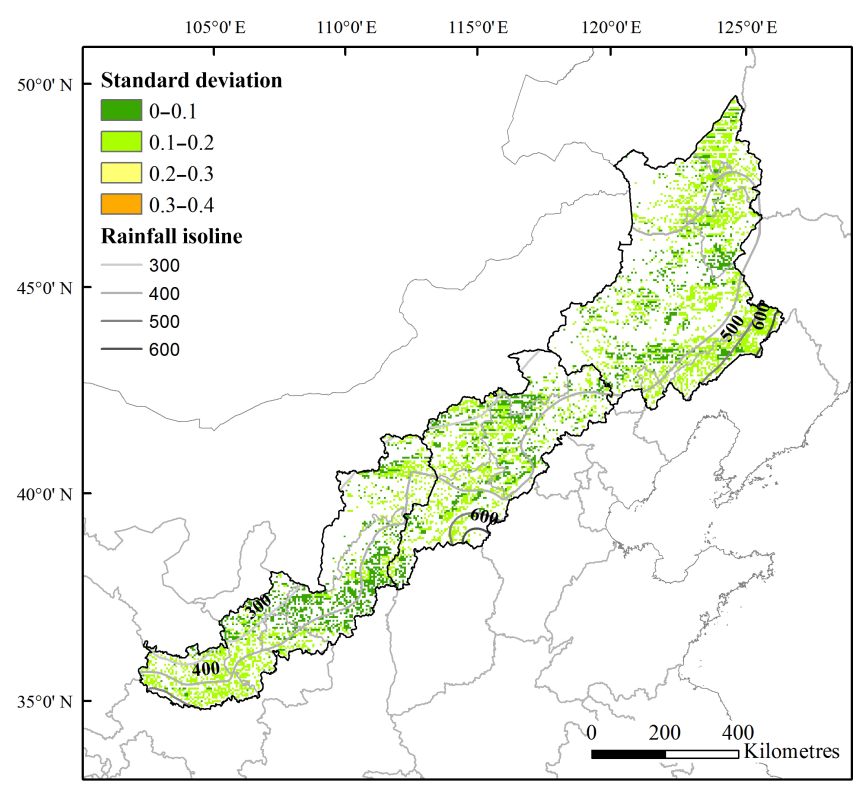

Figure 10. Standard deviation of spring maize yield loss ratio from 1966 to 2011.

represents the decreasing tendency of yield loss ratio. The same increasing tendency as slope of drought hazard intensity index was demonstrated. Conversely, impacted by the reduction effect of the physical vulnerability curve, the rising trend was slightly lower compared with the slope of the drought hazard intensity index. Here the highest values of slope of yield loss ratio (exceeding 0.004 ) centred in the middle part, while the other parts changed from 0 to 0.002 .

To assess the risk of yield loss ratio based on physical vulnerability curve in the farming-pastoral ecotone in Northern China, we calculated the exceeded probability of yield loss ratio for each evaluation unit. With fixed yield loss ratio levels (spring maize yield loss ratio $\geq 0.2$, spring maize drought yield loss ratio $\geq 0.3$, spring maize yield loss ratio $\geq 0.4$ and spring maize yield loss ratio $\geq 0.5$ ), the probability distributions of yield loss ratio are shown in Fig. 12. Seen from the whole study area, under different yield loss ratio levels, the middle part and most regions of the western part were highrisk areas of drought hazard, with the upper limit of probability under yield loss ratio levels from 0.2 to 0.5 being 1,1 , 0.8 and 0.5 . This meant that the drought hazard in these regions would result in a yield loss ratio of 0.2 and 0.3 almost every year. The drought hazard with a yield loss ratio of 0.5 would also occur at least every 2 years. Comparatively, the eastern part within the rainfall isoline from 500 to $600 \mathrm{~mm}$ and the south-west edge of the western part were areas with low probability of drought hazard. The upper limit of probability under 4 hazard levels from 0.2 to 0.5 was $0.8,0.5,0.2$ and 0.2 . Therefore, this part was more likely to meet drought hazard with a yield loss ratio smaller than 0.2. The probability of drought hazard with a yield loss ratio of 0.4 was every 5 years.

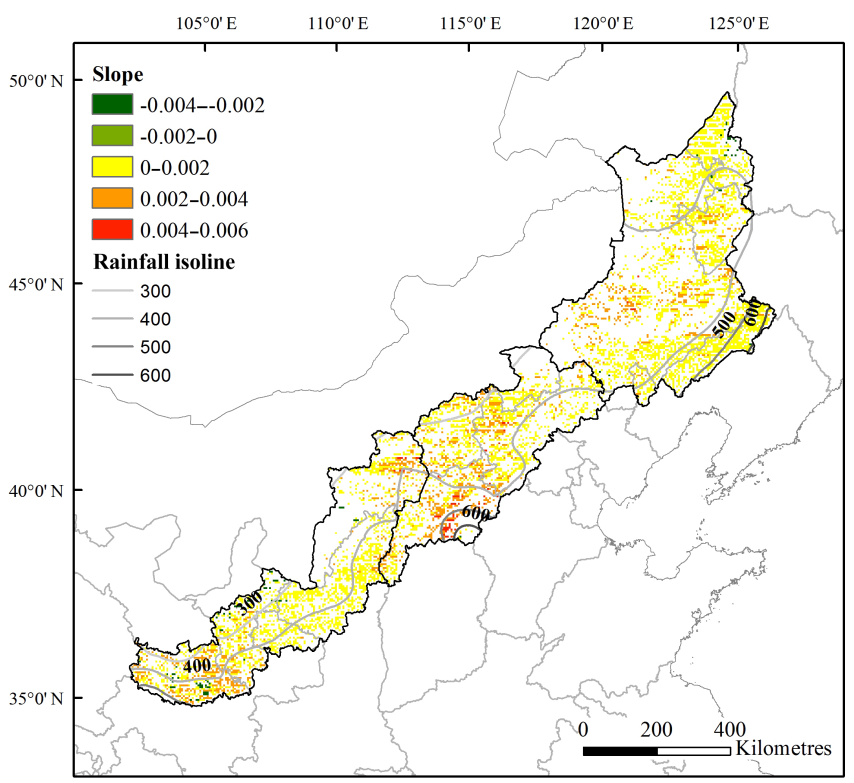

Figure 11. Slope of the linear regression of spring maize yield loss ratio from 1966 to 2011.

In general, the probability distribution of the spring maize yield loss ratio was similar to the probability distribution of drought hazard intensity index. The risk of yield loss ratio dropped from arid to humid regions. Because physical vulnerability curves of all three parts showed reduction effect of drought hazard, the probability of yield loss ratio was slightly lower than that of the drought hazard intensity index.

\section{Discussion}

Since the disaster risk is the function of hazard factor, physical vulnerability, exposure and the disaster reduction capacity of the hazard-affected body, based on the assumption that all maize was exposed to drought hazard, the drought hazard intensity index was calculated with the EPIC model and the physical vulnerability curve was established for different parts of the farming-pastoral ecotone in Northern China. The risk assessment of drought hazard in the study area was discussed from three aspects: the first is the risk assessment of the drought hazard intensity index for spring maize. For the spatial distribution of drought hazard intensity index, it had a negative correlation with precipitation. For most years, $400 \mathrm{~mm}$ rainfall isoline was approximately consistent with a drought hazard intensity index of 0.5 . For regions with rainfall isoline less than $400 \mathrm{~mm}$, drought hazard intensity index here was usually larger than 0.5 , while for regions with a rainfall isoline higher than $400 \mathrm{~mm}$, drought hazard intensity index was usually smaller than 0.5 . For the time series of drought hazard intensity index, the time variation of drought hazard intensity index was consistent with the interannual variation of precipitation. For the eastern part, the interannual 

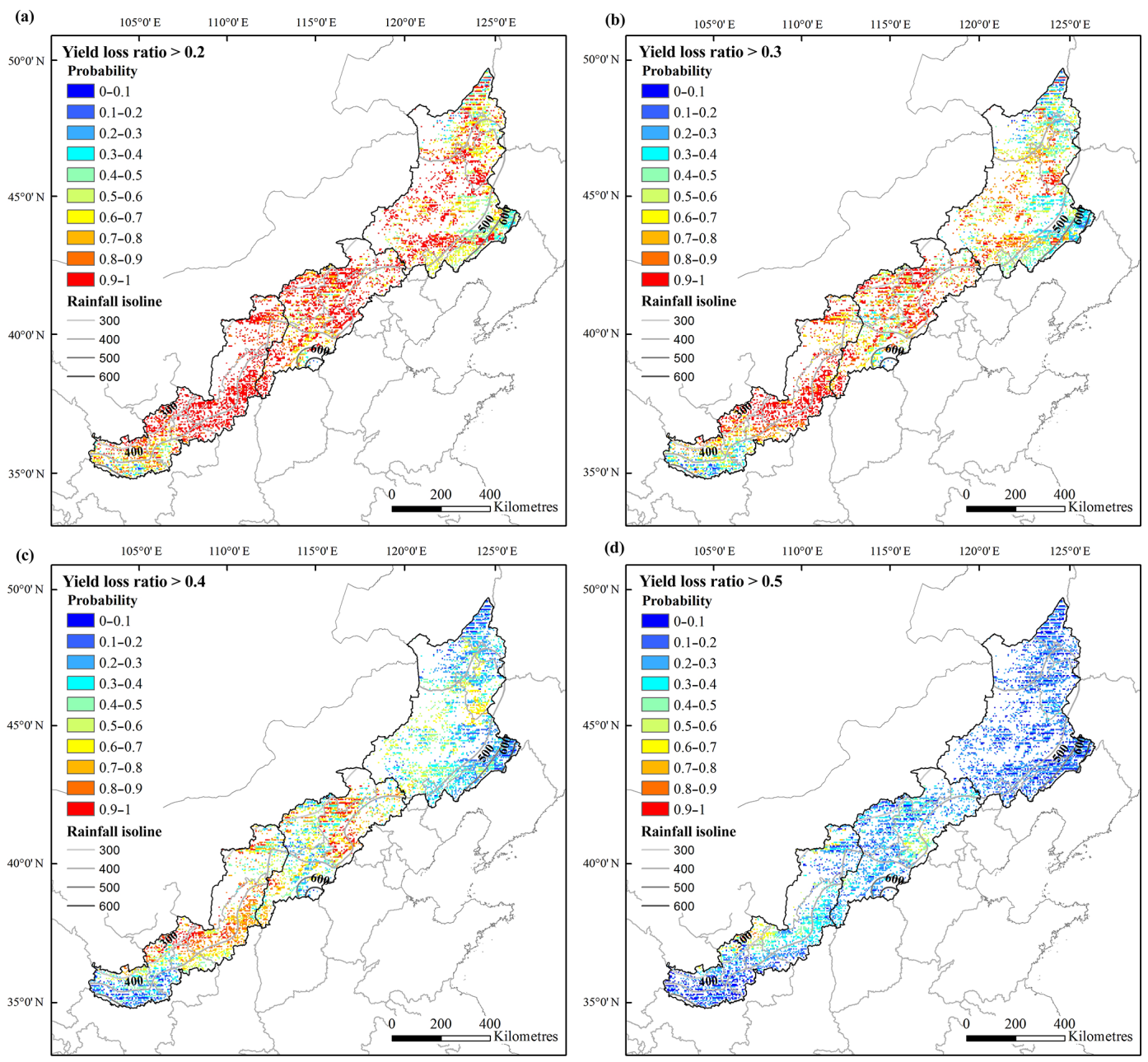

Figure 12. Probability distribution of spring maize yield loss ratio for different yield loss levels. (a) Yield loss ratio $\geq 0.2$, (b) yield loss ratio $\geq 0.3$, (c) Yield loss ratio $\geq 0.4$, (d) yield loss ratio $\geq 0.5$.

variation of precipitation was larger and presented the tendency of worsening drought, making the standard deviation higher. Conversely, for most of the western part, the situation of drought was relatively stable and the interannual variation of precipitation was smaller, showing lower standard deviation of drought hazard intensity index. Also, for most regions in the study area, the drought hazard intensity index presented an increasing tendency throughout years. Drought hazard of a severe degree was spreading west to north-east in recent years. For the probability of drought hazard intensity index, it showed a tendency to decrease from south-west to north-east and the tendency to increase from south-east to north-west along the distribution of rainfall isoline. The second aspect is the physical vulnerability assessment based on the physical vulnerability curve. For three parts of the farming-pastoral ecotone in Northern China, similar physical vulnerability curves were obtained. All of them showed the reduction effect of drought hazard intensity index. The third aspect is the risk assessment of yield loss ratio calcu- lated from the physical vulnerability curve. Adjusted by the physical vulnerability curve of spring maize, the fluctuation of yield loss ratio was smaller compared with that of drought hazard intensity index. Meanwhile, the increasing tendency of yield loss ratio slowed down and the probability of yield loss ratio was reduced. This meant that because of the physical vulnerability, the capacity of spring maize to resist and adapt to drought was improved.

The risk assessments showed that the farming-pastoral ecotone in Northern China is a region with a high risk of agricultural drought and a high sensitivity to climate change. Three different parts showed different spatial and temporal distributions of drought hazard intensity index and yield loss ratio. Drought is one of the most significant manifestations of climate variability in this region, and severe droughts have become more frequent in recent years. To better adapt to drought, measurements can be taken based on the risk assessment in this study: to reduce the drought hazard intensity, the planting environment can be changed, by im- 
proving the ability of irrigation or changing soil property through fertilisation and other tillage methods, for example. To reduce physical vulnerability of crops to agricultural drought, improved varieties of crops can be developed to promote drought-enduring and drought-resistant crops. To reduce crop exposure to drought, planting structure can be adjusted during the planting process.

The uncertainty of this study mainly comes from the simulation of the EPIC model and the construction of the physical vulnerability curve. For the EPIC model, the uncertainties are from the model itself and input data like meteorological data, soil data and field management data. For the construction of the physical vulnerability curve, the uncertainty is mainly due to the limitation of selected scenarios.

The calculation of the physical vulnerability curve for agricultural drought proposed in this method provides a probability to assess drought risk quantitatively. Compared with the previous method, a more accurate drought hazard intensity index was added. According to constructive factors of disaster risk, under the condition of total exposure, the risk assessment was conducted from the drought hazard intensity index, physical vulnerability and the yield loss ratio calculated from the physical vulnerability curve, which gave a synthetic assessment of risk of physical vulnerability to agricultural drought of the farming-pastoral ecotone in Northern China. For further study, a larger study area including southern and northern parts of China will be selected to better assess drought risk and describe the impact of climate change on agriculture along different latitudes.

\section{Conclusion}

This study proposed a method to calculate the physical vulnerability curve based on the drought hazard intensity index and the yield loss ratio from the EPIC model. The genetic parameters of spring maize were first calculated according to the statistical yearbook. Then a water-deficit experiment on different growth stages was conducted to get the yield loss contribution rate. The drought hazard intensity index was also calculated from the daily water stress and yield loss contribution rate for different growth stages. After this, the yield loss ratio was obtained from the difference of yield with two different simulated scenarios using the EPIC model (one was sufficient irrigation and the other one was no irrigation). Then sites under different drought hazard intensities were selected. A logistic model was used to build the relationship between hazard and loss and simulate the physical vulnerability curve. Based on the function of disaster risk, under the condition of total exposure, the risk assessment of agricultural drought in the farming-pastoral ecotone in Northern China was conducted from the drought hazard intensity index and physical vulnerability curve. Seen from the drought hazard intensity index, the risk of agricultural drought represented negative correlation with the precipitation. The intensity of drought hazard has kept rising for the past 46 years and drought hazard with severe extent has been spreading from south-west to north-east gradually. The probability distribution of drought hazard intensity index decreased from southwest to north-east and increased from south-east to northwest along the rainfall isoline. For the physical vulnerability curve, its reduction effect in three parts of the farmingpastoral ecotone in Northern China helped reduce drought hazard vulnerability in spring maize. For the curve of risk of yield loss ratio based on physical vulnerability, the probability was lower compared with the drought hazard intensity index, which shows the capacity of spring maize to resist drought and its adaptation to drought. Overall, the farmingpastoral ecotone in Northern China is highly sensitive and very fragile to climate change because of its location in several different transitional zones. Risk assessment of physical vulnerability to agricultural drought in this region can help people better understand physical vulnerability to agricultural drought and can also promote measurements from different fields to adapt to the climate change.

\section{Data availability}

The meteorological data are applied from China meteorological data sharing service system of the China Meteorological Administration (http://data.cma.cn/). The spatial distribution of soil is got from Institute of Soil Science Chinese Academy of Sciences. The soil properties is got from Chinese Soil Genus Records. The Land-use map is got from Institute of Remote Sensing and Digital Earth Chinese Academy of Sciences. The statistical agricultral data is got from China Statistical Yearbook.

Acknowledgements. This work was supported by a grant entitled "Study on Agricultural Drought Risk Formation Mechanism of the Rain-fed Agricultural Typical Area in China" (41001059) from the National Science and Technology Foundation. We also thank the China Meteorological Administration (CMA) for sharing data.

Edited by: S. Fuchs

Reviewed by: two anonymous referees

\section{References}

Angstrom, A.: Solar and terrestrial radiation. Report to the international commission for solar research on actinometric investigations of solar and atmospheric radiation, Q. J. Roy. Meteor. Soc., 50, 121-126, 1924.

Antwi-Agyei, P., Fraser, E. D., Dougill, A. J., Stringer, L. C., and Simelton, E.: Mapping the vulnerability of crop production to drought in Ghana using rainfall, yield and socioeconomic data, Appl. Geogr., 32, 324-334, 2012.

AQSIQ/SAC: GB/T 21986-2008 Assessment of agroclimate impact: Classification method of annual crop climate types, Beijing, 
General Administration of Quality Supervision, Inspection and Quarantine of the People's Republic of China/Standardization Administration of the Peoples Republic of China, 2008.

Blaikie, P. C. and Cannon, T.: At Risk, natural hazards, people's vulnerability and disasters, Disaster and society from hazard assessment to risk reduction, Berlin, 75-82, Routledge, 2014.

Douglas, J.: Physical vulnerability modelling in natural hazard risk assessment, Nat. Hazards Earth Syst. Sci., 7, 283-288, doi:10.5194/nhess-7-283-2007, 2007.

FAO: The State of Food Insecurity in the World 2001, in: The multiple dimensions of food security, Rome, 2001.

FAO: The State of Food Insecurity in the World 2013. The multiple dimensions of food security, Rome, 2013.

Füssel, H.-M.: Vulnerability: a generally applicable conceptual framework for climate change research, Global Environ. Chang., 17, 155-167, 2007.

Gassman, P., Williams, W., Benson, J. R., Izaurralde, V. W., Hauck, R. C., Jones, L. C., Atwood, C. A., Kiniry, J. D., Flowers, J. R., and Flowers, J. D.: Historical development and applications of the EPIC and APEX models, Center for Agricultural and Rural Development, Iowa State University, 2005.

Geng, Q., Wu, P., Zhang, Q., Zhao, X., and Wang, Y.: Dry/wet climate zoning and delimitation of arid areas of Northwest China based on a data-driven fashion, J. Arid Land, 6, 287-299, 2014.

Herrmann, S. M., Anyamba, A., and Tucker, C. J.: Recent trends in vegetation dynamics in the African Sahel and their relationship to climate, Global Environ. Chang., 15, 394-404, 2005.

Hufkens, K., Scheunders, P., and Ceulemans, R.: Ecotones in vegetation ecology: methodologies and definitions revisited, Ecol. Res., 24, 977-986, 2009.

IPCC: Climate Change 2014: Synthesis Report, Contribution of Working Groups I, II and III to the Fifth Assessment Report of the Intergovernmental Panel on Climate Change, 2014.

Izaurralde, R. C., Mcgill, W. B., and Williams, J.: Development and application of the EPIC model for carbon cycle, greenhouse-gas mitigation, and biofuel studies, Pacific Northwest National Laboratory (PNNL), Richland, WA, 2012.

Jain, V., Pandey, R. P., and Jain, M.: Spatio-temporal assessment of vulnerability to drought, Nat. Hazards, 76, 443-469, doi:10.1007/s11069-014-1502-z, 2015.

Jia, H., Wang, J., Cao, C., Pan, D., and Shi, P.: Maize drought disaster risk assessment of China based on EPIC model, Int. J. Dig. Earth, 5, 488-515, 2012.

Karavitis, C. A., Tsesmelis, D. E., Skondras, N. A., Stamatakos, D., Alexandris, S., Fassouli, V., Vasilakou, C. G., Oikonomou, P. D., Gregorič, G., and Grigg, N. S.: Linking drought characteristics to impacts on a spatial and temporal scale, Water Policy, 16, 11721197, 2014.

Kark, S.: Ecotones and ecological gradients, in: Ecological Systems, Springer, 147-160, 2013.

Kellner, O. and Niyogi, D.: FORAGES AND PASTURES SYMPOSIUM: Assessing drought vulnerability of agricultural production systems in context of the 2012 drought, J. Anim. Sci., 92, 2811-2822, 2014.

Kim, H., Park, J., Yoo, J., and Kim, T.-W.: Assessment of drought hazard, vulnerability, and risk: a case study for administrative districts in South Korea, J. Hydroenviron. Res., 9, 28-35, 2015.
Liu, J.-H., Gao, J.-X., Lv, S.-H., Han, Y.-W., and Nie, Y.-H.: Shifting farming - pastoral ecotone in China under climate and land use changes, J. Arid Environ., 75, 298-308, 2011.

Lu, W. and Jia, G.: Fluctuation of farming-pastoral ecotone in association with changing East Asia monsoon climate, Climatic Change, 119, 747-760, 2013.

Murthy, C., Yadav, M., Ahamed, J. M., Laxman, B., Prawasi, R., Sai, M. S., and Hooda, R.: A study on agricultural drought vulnerability at disaggregated level in a highly irrigated and intensely cropped state of India, Environ. Monit. Assess., 187, 1$14,2015$.

Piao, S., Ciais, P., Huang, Y., Shen, Z., Peng, S., Li, J., Zhou, L., Liu, H., Ma, Y., and Ding, Y.: The impacts of climate change on water resources and agriculture in China, Nature, 467, 43-51, 2010.

Prescott, J.: Evaporation from a water surface in relation to solar radiation, T. Roy. Soc. South Aust., 64, 114-118, 1940.

Pumijumnong, N. and Arunrat, N.: Simulating the rice yield change in Thailand under SRES A2 and B2 scenarios with the EPIC model, J. Agri-Food Appl. Sci., 1, 119-125, 2013.

Rian, S., Xue, Y., MacDonald, G. M., Touré, M. B., Yu, Y., De Sales, F., Levine, P. A., Doumbia, S., and Taylor, C. E.: Analysis of climate and vegetation characteristics along the Savanna-Desert ecotone in Mali using MODIS data, GISci. Remote Sens., 46, 424-450, 2009.

Rinaldi, M. and De Luca, D.: Application of EPIC model to assess climate change impact on sorghum in southern Italy, Ital. J. Agron., 7, 74-85, 2012.

Sharma, U. and Patwardhan, A.: Methodology for identifying vulnerability hotspots to tropical cyclone hazard in India, Mitig. Adapt. Strat. Gl., 13, 703-717, 2008.

Shi, W., Tao, F., Liu, J., Xu, X., Kuang, W., Dong, J., and Shi, X.: Has climate change driven spatio-temporal changes of cropland in northern China since the 1970s?, Climatic Change, 124, 163177, 2014.

Simelton, E., Fraser, E. D., Termansen, M., Forster, P. M., and Dougill, A. J.: Typologies of crop-drought vulnerability: an empirical analysis of the socio-economic factors that influence the sensitivity and resilience to drought of three major food crops in China (1961-2001), Environ. Sci. Policy, 12, 438-452, 2009.

Skaggs, T., Arya, L., Shouse, P., and Mohanty, B.: Estimating particle-size distribution from limited soil texture data, Soil Sci. Soc. Am. J., 65, 1038-1044, 2001.

UNDP: Reducing Disaster Risk: A Challenge for Development - a Global Report, United Nations Development Programme, 2004.

UNISDR Terminology on Disaster Risk Reduction, available at: https://www.unisdr.org/we/inform/terminology, 2009.

Uzielli, M., Nadim, F., Lacasse, S., and Kaynia, A. M.: A conceptual framework for quantitative estimation of physical vulnerability to landslides, Eng. Geol., 102, 251-256, 2008.

Wang, Z., He, F., Fang, W., and Liao, Y.: Assessment of physical vulnerability to agricultural drought in China, Nat. Hazards, 67, 645-657, 2013.

Wang, Z., Jiang, J., Liao, Y., and Deng, L.: Risk assessment of maize drought hazard in the middle region of farming-pastoral ecotone in Northern China, Nat. Hazards, 76, 1515-1534, 2015.

Wheeler, T. and von Braun, J.: Climate change impacts on global food security, Science, 341, 508-513, 2013. 
Xiong, W., Balkovič, J., van der Velde, M., Zhang, X., Izaurralde, R. C., Skalský, R., Lin, E., Mueller, N., and Obersteiner, M.: A calibration procedure to improve global rice yield simulations with EPIC, Ecol. Model., 273, 128-139, 2014.

$\mathrm{Xu}, \mathrm{D} ., \mathrm{Li}, \mathrm{C}$. , Song, X., and Ren, H.: The dynamics of desertification in the farming-pastoral region of North China over the past 10 years and their relationship to climate change and human activity, CATENA, 123, 11-22, 2014.

Ye, Y. and Fang, X.: Boundary shift of potential suitable agricultural area in farming-grazing transitional zone in Northeastern China under background of climate change during 20th century, Chinese Geogr. Sci., 23, 655-665, 2013.
Zhao, H., Zhao, X., Zhang, T., and Zhou, R.: Boundary line on agro-pasture zigzag zone in north china and its problems on ecoenvironment, Adv. Earth Sci., 17, 739-747, 2002.

Zou, X., Zhai, P., and Zhang, Q.: Variations in droughts over China: 1951-2003, Geophys. Res. Lett., 32, L04707, doi:10.1029/2004GL021853, 2005. 